\title{
In memoriam \\ Ralf Dahrendorf: un clàssic del segle XX
}

El 17 de juny passat va morir a Colònia (Alemanya) Ralf Dahrendorf (Hamburg, 1929-2009), un sociòleg, pensador liberal (juntament amb Isaiah Berlin i Norberto Bobbio, entre d'altres) i home polític (a Alemanya, el Regne Unit, la Unió Europea) que va fer evolucionar la sociologia des de Marx i Weber fins a la visió conflictivista de la societat. Coneixedor de l'obra d'aquests dos clàssics, gran part de la producció científica sociològica de la segona meitat del segle XX no es pot concebre sense la influència d'aquest gran pensador.

Per a Dahrendorf, Marx no distingeix entre relacions de propietat i relacions d'autoritat. No distingeix entre propietat legal dels mitjans de producció i control real del procés productiu. No distingeix entre formació de les classes socials i la lluita política que se'n deriva, i formació de grups d'interessos i conflicte social. El model marxista o teoria de les classes socials és massa determinista en sentit econòmic i és massa restringit en l'anàlisi de les societats industrials del segle XIX. Al segle XX, el sector industrial de l'economia comparteix importància amb el sector dels serveis. El conflicte a la indústria no deriva necessàriament en conflicte polític, sinó que és susceptible de negociació. S'ací que a les societats (avançades, modernitzades) del segle XX no es produeix l'homogeneïtat interna ni la polarització en dues classes socials antagòniques, com preveia Marx, sinó que s'hi forma un nova classe mitjana creixent en nombre de components i en influència en la societat per l'augment dels salaris reals i la diferenciació interna (especialització i qualificació progressiva dels treballadors segons les demandes del procés productiu). El conflicte industrial no esdevé necessàriament un conflicte polític, ni se sobreposa l'un a l'altre. El conflicte entre els capitalistes i els obrers s'institucionalitza a través dels sindicats. Aquestes organitzacions representen els interessos dels treballadors com a classe social o com a individus en la mateixa situació social en el procés productiu. L'arrel del debat en els anys vuitanta i noranta sobre el corporativisme en sociologia i ciència política es troba en la capacitat dels sindicats de negociar el conflicte amb les patronals, seguint unes regles del joc $\mathrm{i}$ admetent l'estat (el govern) com a mediador. La projecció de Dahrendorf és clara en debats científics pregons de finals de segle. 
De Weber recull els conceptes clau de poder i d'autoritat i posa un èmfasi especial en el darrer, ja que li permet definir la seva unitat bàsica d'estructura social: els grups d'interessos. Autoritat és la probabilitat que una ordre d'un contingut específic sigui obeïda per un determinat grup de persones. En tota societat industrial, algunes ocupacions (i, per extensió, posicions socials) són dipositàries del dret a exercir el control sobre els altres. Així, la distribució diferencial d'autoritat és el que es converteix en un factor determinant dels conflictes socials. Autoritat és la relació legitimada de dominació i subjecció.

L'aplicació creixent de tecnologies noves, la necessitat per al procés productiu de creixent especialització i formació dels treballadors, la diferenciació en el si de la classe obrera, el creixement dels salaris reals, la mobilitat funcional i geogràfica necessària i possible per al procés productiu, la mobilitat social, la voluntat mútua d'obrers i capitalistes de controlar i negociar el conflicte; són els canvis que distingeixen la societat industrial del segle XIX de la del segle XX. Equidistant de l'enfocament marxista del conflicte entre classes antagòniques i del model funcionalista d'integració social, Dahrendorf parla de societat (i més concretament d'associació imperativament coordinada) on el conflicte i el canvi social són ubics. El factor determinant del conflicte social és la distribució diferencial d'autoritat en la societat o en una organització entesa com a associació imperativament coordinada, és a dir, unida i mantinguda per la força de la coerció. En tota societat o organització, algunes posicions (corresponents a ocupacions) són dipositàries del dret a exercir control sobre les que en depenen, generalment situades en posicions jeràrquicament inferiors. D'ací que es formin grups de conflicte que es corresponen a grup d'interessos, interessos derivats de l'ocupació i la posició social de cada individu en el procés productiu.

L'èmfasi en l'individu més que no pas en el grup social o en la societat en conjunt és un tret diferencial de Dahrendorf respecte de Marx, Weber i també Comte, Durkheim i Parsons. El conflicte existeix en qualsevol relació social, en qualsevol interacció entre dos o més individus. És un element inherent a les relacions humanes, que no són mai indiferents una vers l'altra. Paral.lelament a Geiger, Dahrendorf posa l'èmfasi en el caràcter positiu del conflicte com a element integrador $\mathrm{i}$ innovador en una societat.

No és un element nefast que duu a la destrucció d'una societat. Ans al contrari, és un dinamitzador, ja que provoca creativitat, desenvolupament de les potencialitats de l'individu i, en conseqüència, del grup, de la comunitat, de la societat. Condueix al canvi social, al progrés.

A banda l'aportació pregona en la reflexió teòrica sociològica sobre les societats del segle Xx, Ralf Dahrendorf va contribuir a la institucionalització internacional i a la visibilització de la sociologia a través de diversos càrrecs acadèmics, com el de degà de la London School of Economics and Social Sciences, entre 1974 i 1984, o de la Universitat d'Oxford, dos dels centres de coneixement en sociologia més prestigiosos del món. En l'esfera política, assessorà dirigents polítics, com ara el primer ministre britànic Toni Blair, i inspirà programes d'actuació política. Sempre va donar prioritat a les institucions democrà- 
tiques davant el contacte directe, de caire populista, amb el poble, per reforçar els valors que fonamenten l'ordre liberal que Dahrendorf preconitzava.

La Facultat de Ciències Polítiques i de Sociologia de la Universitat Autònoma de Barcelona va tenir l'honor de rebre la visita de Ralf Dahrendorf durant el mandant de l'exrector Josep M. Vallès, aleshores degà de la Facultat. El curs 1989-1990 fou inaugurat amb una classe magistral de Ralf Dahrendorf. És una satisfacció per a la nostra facultat el fet que, fa vint anys, de la mà del degà Vallès, es reconegués públicament l'obra i la figura d'un clàssic del segle XX com Ralf Dahrendorf. 